\title{
M-DC8+ Leukocytes - A Novel Human Dendritic Cell Population
}

\author{
Knut Schäkel ${ }^{a}$ Claudia Poppe $^{a}$ Elfriede Mayer ${ }^{b}$ Christine Federle ${ }^{b}$

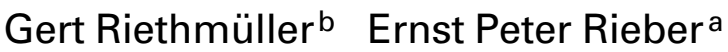 \\ aInstitute for Immunology, Medical Faculty, University of Dresden, and 'Institute for Immunology, \\ University of Munich, Germany
}

\section{Key Words}

Dendritic cell $\cdot$ Cell marker $\cdot$ Human blood $\cdot$ T cell priming

\begin{abstract}
Dendritic cells (DC) constitute a heterogeneous leukocyte population having in common a unique capacity to induce primary $\mathrm{T}$ cell responses and are therefore most attractive candidates for immunomodulatory strategies. Two populations of blood DC (CD11C+ CD123 dim and CD11c- CD123 high) have been defined so far. However, their direct isolation for experimental purposes is hampered by their low frequency and by the lack of selective markers allowing large scale purification from blood. Here we describe the monoclonal antibody (mAb) MDC8, which was generated by immunizing mice with highly enriched blood DC. This mAb specifically reacts with $0.2-1 \%$ of blood leukocytes and enables their direct isolation by a one-step immunomagnetic procedure from fresh mononuclear cells. These cells can be differentiated from T cells, B cells, NK cells and monocytes using lineage-specific antibodies. M-DC8+ cells express HLA class II molecules, CD33 and low levels of the costimulatory molecules CD86 and CD40. Upon in vitro culture M-DC8+ cells spontaneously mature into cells with the phenotype of highly stimulatory cells as documented
\end{abstract}

\begin{tabular}{ll}
\hline KARGER & ( 2000 S. Karger AG, Basel \\
Fax +4161306 1234 & \\
$\begin{array}{l}\text { E-Mail karger@karger.ch } \\
\text { www.karger.com }\end{array}$ & $\begin{array}{l}\text { Accessible online at: } \\
\text { www.karger.com/journals/pat }\end{array}$
\end{tabular}

by the upregulation of HLA-DR, CD86 and CD40; in parallel CD80 expression is induced. M-DC8+ cells display an outstanding capacity to present antigen. In particular, they proved to be excellent stimulators of autologous mixed leukocyte reaction and to activate $T$ cells against primary antigens such as keyhole limpet hemocyanin. Furthermore, they induce differentiation of purified allogeneic cytotoxic $\mathrm{T}$ cells into alloantigen-specific cytotoxic effector cells. While the phenotypical analysis reveals similarities with the two known blood DC populations, the characteristic expression of Fc $\gamma$ RIII (CD16) and the M-DC8 antigen clearly defines them as a novel population of blood DC. The mAb M-DC8 might thus be a valuable tool to determine circulating DC for diagnostic purposes and to isolate these cells for studies of antigenspecific $\mathrm{T}$ cell priming.

Copyright ( 92000 S. Karger AG, Basel

\section{Introduction}

Dendritic cells (DC) represent a unique cell population linking the innate immune system with the adaptive, specific immune system. In particular they are capable of activating primary antigen-specific $\mathrm{T}$ cell responses and control their differentiation into Th1 and Th2 cells. Conventional strategies such as depletion of lineage marker-

Dr. Ernst Peter Rieber

Institute for Immunology

Medical Faculty, University of Dresden

Karl-Marx-Strasse 3

D-01101 Dresden (Germany) 
positive cells and subsequent isolation of MHC class IIexpressing cells led to the definition of two major populations of DC regarded as a myeloid and lymphoid lineage [1]. Phenotypically they are distinguished by the reciprocal expression of CD11c and CD123. Based on their differential capacity as mature cells to induce Th1 and Th2 cells, the myeloid DC lineage was designated as DC1 $\left(\mathrm{CD} 11 \mathrm{c}+\mathrm{CD} 123^{\text {low }}\right)$ and the lymphoid lineage as DC2 (CD11c- CD123high) [2]. However, when using freshly isolated DC this effect could not be observed [3]. Despite many attempts no specific surface molecules have thus far been characterized, which could serve as a handle to isolate these DC subsets.

We succeeded in generating a novel mAb M-DC8, which turned out to be a selective marker for $0.2-1 \%$ of blood leukocytes. This small cell population shows characteristic morphologic and functional features of DC and can be directly isolated from fresh PBMC with the help of the mAb M-DC8. M-DC8+ cells express CD16 not previously described for $\mathrm{DC}[1]$. This finding, together with the negative M-DC8 staining of DC1 and DC2 defines M-DC8+ cells as a new subpopulation of blood DC.

\section{Methods}

\section{Cell Culture}

Cells were cultured in RPMI 1640 containing $2 \mathrm{~m} M L$-glutamine, $1 \%$ nonessential amino acids (Biochrom, Berlin, Germany), $100 \mathrm{U} /$ $\mathrm{ml}$ penicillin, $100 \mu \mathrm{g} / \mathrm{ml}$ streptomycin (Gibco, Eggenstein, Germany) and $10 \%$ human $\mathrm{AB}$ serum (c.c.pro, Neustadt, Germany).

\section{Isolation of Cells}

Human PBMC were isolated from buffy coat preparations by Ficoll-Hypaque (Pharmacia, Freiburg, Germany) density centrifugation. M-DC8+ cells were obtained by incubating PBMC with M-DC8 hybridoma supernatant, washed with PBS and labeled with rat antimouse IgM microbeads (Miltenyi Biotec, Bergisch-Gladbach, Germany). After washing labeled M-DC8+ cells were purified by two rounds of magnetic cell sorting using an LS and RS separation column. Using the nonmagnetic cell preparation monocytes were isolated with the aid of anti-CD14 microbeads. T cells were isolated by rosetting with sheep red blood cells treated with aminoethyl isothiuronium bromide (Sigma, Deisenhofen, Germany). From this population CD $8+\mathrm{T}$ cells $>98 \%$ purity were prepared by depleting CD4+ cells as rosettes with bovine red blood cells coated with the $\mathrm{CD} 4 \mathrm{mAb}$ M-T310.

\section{Flow-Cytometric Analysis}

For three-color fluorescence analysis of M-DC8+ cells, blood cells were incubated with undiluted M-DC8 hybridoma supernatant followed by anti FITC-conjugated goat $\mathrm{F}\left(\mathrm{ab}^{\prime}\right) 2$ anti-mouse IgM (Coulter-Immunotec, Hamburg, Germany). After washing with PBS 0.1\% $\mathrm{NaN}_{3}$ cells were incubated with mAb specific for HLA-DR, CD3, CD14, CD16, or CD19 (all from Pharmingen, Hamburg, Germany) followed by lysis of erythrocytes.

\section{$T$ Cell Activation}

Graded numbers of purified of APC were cocultured with purified T lymphocytes $\left(1 \times 10^{5}\right)$ for 7 days in $0.2 \mathrm{ml}$ medium in roundbottomed microtiter plates (Corning, New York, N.Y., USA). Proliferation of $\mathrm{T}$ cells was determined during the last $15 \mathrm{~h}$ by uptake of $\left[{ }^{3} \mathrm{H}\right]$ thymidine $(2 \mu \mathrm{Ci} /$ well; NEN, Cologne, Germany). Keyhole limpet hemocyanin (KLH) was added at a concentration of $1 \mu \mathrm{g} / \mathrm{ml}$. Alloantigen-specific CTL were induced by coculture of purified CD8+ T cells with allogeneic APC. After 7 days cells were harvested and tested for CTL activity against ${ }^{51} \mathrm{Cr}$-labeled PHA blast of stimulator origin.

\section{Cytochemistry}

$\alpha$-Naphthyl acetate esterase (ANAE) activity was revealed by incubation with $p$-rosaniline and naphthol AS-D chloroacetate supplied in a test kit (Sigma). Mayer's hemalum was used for counterstaining. Benzidine-identified myeloperoxidase (MPO) activity and Giemsa stain were used to identify cell nuclei.

\section{Results}

\section{Phenotype of $M-D C 8+$ Cells}

Mice were immunized with $\mathrm{T}$ and $\mathrm{B}$ cell-depleted HLA-DR+ PBMC. The hybridoma M-DC8 (isotype IgM) was selected out of more than $6 \times 10^{3}$ hybridoma supernatants due to its staining of a HLA-DR + cell population accounting for $0.2-1 \%$ of total blood leukocytes (fig. 1a, b) [4]. M-DC8+ cells can be clearly differentiated from T cells, B cells, monocytes, NK cells and granulocytes by their characteristic size and granularity and particularly by using mAb specific for HLA-DR, CD3, CD14 and CD19 (fig. 1a, b). Interestingly, M-DC8+ cells express FcrRIII (CD16) (fig. 1b), which is rapidly downregulated upon culture (not shown). Previously defined populations of blood DC are visualized by gating on HLA-DR+ cells negative for CD16, CD3, CD14 and CD19 (upper left quadrant of fig. 1c) which show no M-DC8 staining (fig. 1d).

\section{Stimulation of T Cells}

In order to investigate the capacity of M-DC8+ cells to promote the proliferation of $\mathrm{T}$ cells it was necessary to isolate these cells at high purity. Given the specificity of the mAb M-DC8 and its high avidity binding due to the IgM isotype, we chose a direct isolation method from PBMC employing an immunomagnetic separation (Miltenyi) yielding $>97 \%$ pure M-DC $8+$ cells [4].

As shown in figure 1e, M-DC8+ cells but not monocytes induced a significant proliferation of autologous $\mathrm{T}$ cells, a function ascribed to DC. Provided that DC are best characterized by their unique capacity to prime antigen-specific $\mathrm{T}$ cell responses, we investigated the induc- 

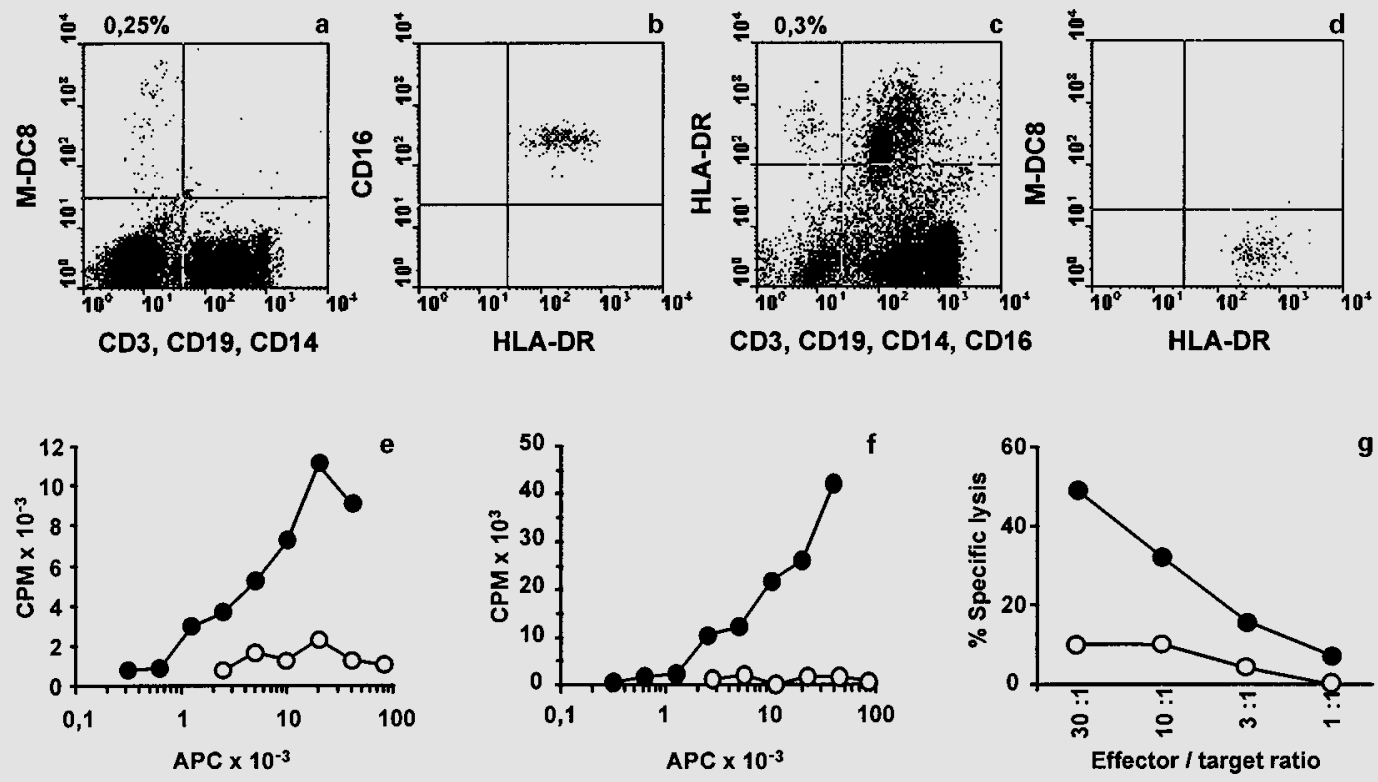

Fig. 1. Flow-cytometric analysis of human peripheral blood leukocytes using the mAb M-DC8 and stimulation of T cell responses by M-DC8+ cells [4]. In $\mathbf{b}$ gating was done on M-DC8+ cells revealed in $\mathbf{a}$ and in $\mathbf{d}$ gating was done on previously identified DC depicted in the upper left quadrant of $\mathbf{c}$. T cell stimulation was done $(\mathbf{e}, \mathbf{f}, \mathbf{g})$ using M-DC $8+$ cells $(-)$ or CD14+ monocytes $(O)$ as APC. Proliferation of autologous T cells in the absence (e) or presence of KLH (f)

tion of a $\mathrm{T}$ cell response specific for the neoantigen KLH. In these assays M-DC8+ cells in contrast to CD14+ monocytes were efficient inducers of a KLH-specific T cell response (fig. 1f). Furthermore, we tested the capacity of M-DC8+ cells to prime CD8+ cytotoxic T cells in vitro (fig. 1d). In these assays, M-DC $8+$ cells or monocytes were cocultured with purified allogeneic CD8+ T cells. After 7 days cytotoxicity was determined using ${ }^{51} \mathrm{Cr}$-labeled stimulator-type PHA blasts as target cells. As shown in figure $1 \mathrm{~g}, \mathrm{M}-\mathrm{DC} 8+$ cells were by far more efficient than monocytes in activating alloantigen-specific cytotoxic effector cells.

\section{Enzyme Cytochemistry}

Cytospins of freshly isolated M-DC8+ cells and monocytes were used to demonstrate ANAE and MPO. While CD14+ monocytes, as also known for macrophages, showed an intense ANAE reaction and were faintly positive for MPO, M-DC8+ cells as attributed to DC were negative for both enzyme activities (fig. 2). was determined by $15 \mathrm{~h}\left[{ }^{3} \mathrm{H}\right]$ thymidine uptake. Values of $\mathrm{T}$ cell proliferation in the absence of antigen were substracted from the total cpm (f). Alloantigen-specific cytotoxic T cells $(\mathbf{g})$ were induced coculturing CD8+ T cells with allogeneic APC. Cytotoxicity of T lymphocytes was tested against ${ }^{51} \mathrm{Cr}$-labeled stimulator-type PHA blasts. Reproduced with permission [4].

\section{Discussion}

Here we report on a new population of DC defined by the novel mAb M-DC8. The mAb was obtained by immunizing mice with mononuclear cells highly enriched for DC. It specifically reacted with a small cellular leukocyte subset comprising $0.2-1 \%$ of total blood leukocytes which was HLA-DR+ and lacked expression of common lineagespecific markers. Supported by the characteristic light scatter profile, the mAb M-DC8 was considered as a good candidate marker for human blood DC.

Two human blood DC populations have been defined so far: $\mathrm{DC} 1\left(\mathrm{CD} 11 \mathrm{c}+\mathrm{CD} 123^{\text {low }}\right)$ are of myeloid origin, representing Langerhans cells and interstitial DC, whereas DC2 (CD11c- CD123 high) previously described as plasmacytoid $\mathrm{T}$ cells or plasmacytoid monocytes are identical to the natural interferon- $\alpha$-producing cells representing lymphoid DC [3]. Based on the expression of CD13, CD33 (not shown) M-DC8+ cells seemed to be more closely linked to the myeloid DC population. However, several lines of evidence suggest that the mAb 


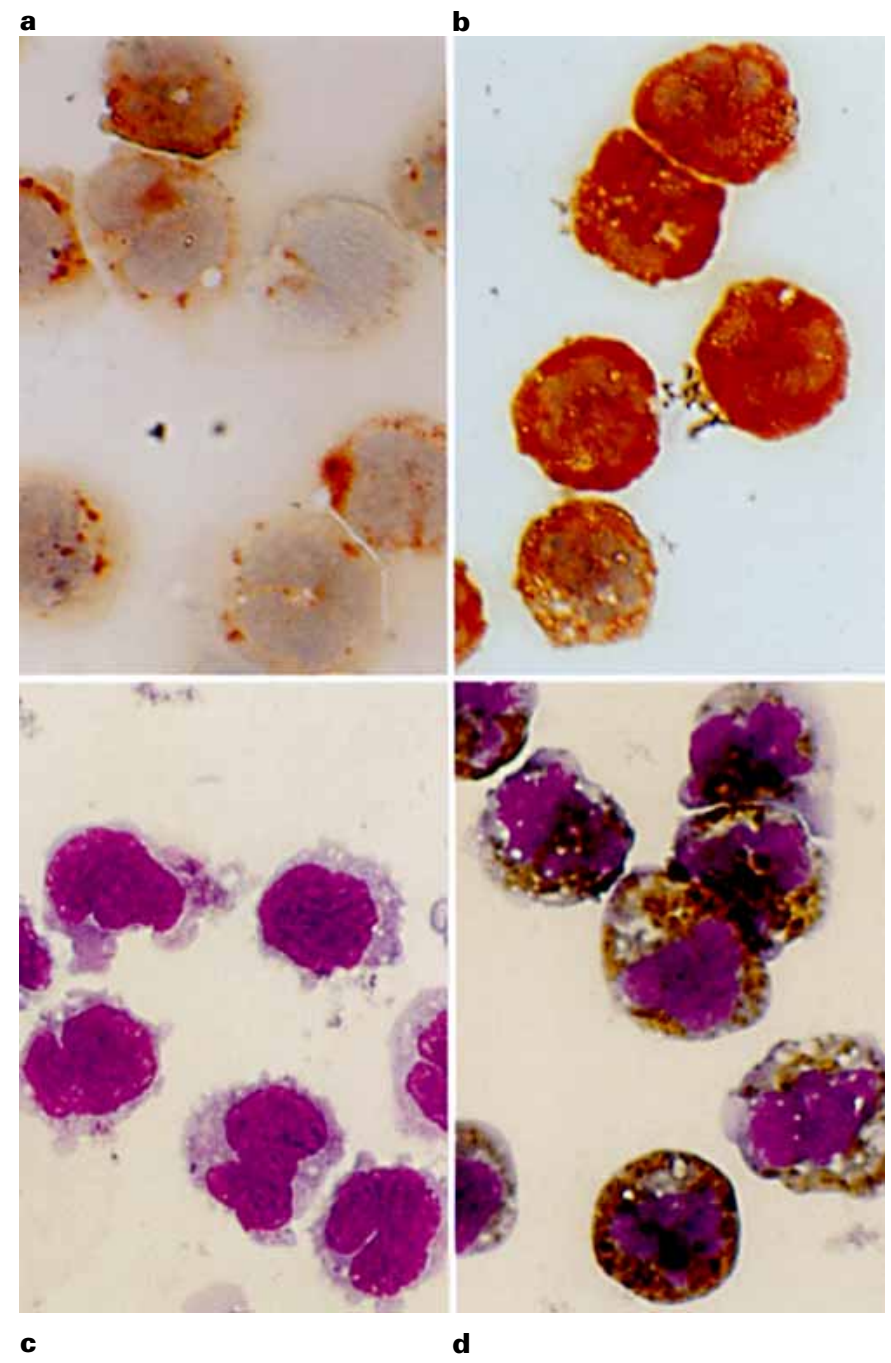

Fig. 2. Enzyme cytochemistry. Cytospins of M-DC $8+$ cells $(\mathbf{a}, \mathbf{c})$ and monocytes $(\mathbf{b}, \mathbf{d})$ were tested for $\operatorname{ANAE}(\mathbf{a}, \mathbf{b})$ or MPO activity (c, d). Reproduced with permission [4].

M-DC8 is a marker specific for a novel population of blood DC: (1) the mAb M-DC8 does not stain DC1 or DC2; (2) M-DC8+ cells express CD16, and (3) monocytederived DC are negative for M-DC8 staining (not shown). Concerning the origin of M-DC8+ cells it is of note that small numbers of M-DC8+ cells develop in vitro from CD34+ stem cell cultures supplied with GM-CSF and TNF- $\alpha$ (unpubl. observation).

The mAb M-DC8 seems to be unique among the increasing number of DC-related or DC-specific reagents. In contrast to CD83 and CMRF-44, both induced upon culture and fascin/p55, which is confined to the cytoplasm, the M-DC8-Ag is already expressed on circulating blood cells, enabling the direct isolation of this cell population without additional in vitro manipulation. Further- more, the M-DC8 antigen is not induced on other PBMC during in vitro culture, making it possible to follow MDC8+ cells.

In a variable percentage ( $25 \%$ donor 1 and $50 \%$ donor 2) M-DC8+ cells are found among a cell population regarded as macrophage-like cells which may be best characterized by their expression of CD16 and HLA-DR [5]. However, the absence of ANAE and MPO activity and the lack of M-DC8 expression by macrophages clearly discriminate M-DC 8 + cells from macrophages.

M-DC8+ cells displayed an outstanding antigen-presenting capacity. In contrast to monocytes, M-DC8+ cells efficiently stimulated the proliferation of autologous $\mathrm{T}$ cells, and furthermore, they induced a marked $\mathrm{T}$ cell response specific for the neoantigen KLH. In addition, a coculture of purified CD8 $+\mathrm{T}$ cells with allogeneic M-DC 8+ cells led to the generation of alloantigen-specific cytotoxic $\mathrm{T}$ cells independent of the help provided by CD4+ T cells. Taken together, M-DC8+ cells represent a distinct population of human blood DC which has previously not been recognized. Based on the data obtained so far M-DC8+ cells seem to be more closely related to DC1 rather than to DC2. However, M-DC8+ cells can be distinguished from other professional APC by the high density expression of Fc $\gamma$ RIII which may equip these cells with particular functional features, e.g. efficient uptake of antigens complexed with antibodies. Identification of DC subpopulations, definition of their activation requirements and their capacity to program Th1 and Th2 cells may expand our knowledge of the regulation of specific immune responses.

\section{References}

1 O'Doherty U, Peng A, Gezelter S, Swiggard WJ, Betjes M, Bhardwaj N, Steinmann R: Human blood contains two subsets of dendritic cells, one immunologically mature and the other immature. Immunology 1994;82:487-493.

2 Rissoan M-C, Soumelis V, Kadowaki N, Grouard G, Briere F, de Waal Malefyt R, Liu Y-J: Reciprocal control of T helper cell differentiation. Science 1999;283:1183-1186.

3 Cella M, Jarrossay D, Fachetti F, Alebardi O, Nakajimas H, Lanzavecchia A, Collona M: Plasmacytoid monocytes migrate to inflamed lymph nodes and produce large amounts of type I interferon. Nat Med 1999;5:919-923.

4 Schäkel K, Mayer E, Federle C, Schmitz M, Riethmüller G, Rieber EP: A novel dendritic cell population in human blood: One-step immunomagnetic isolation by a specific mAb (MDC8) and in vitro priming of cytotoxic T lymphocytes. Eur J Immunol 1998;28:4084-4093.

5 Ziegler-Heitbrock H-W: Heterogeneity of human blood monocytes: The CD14+ CD16+ subpopulation. Immunol Today 1996;17:424-428.

Schäkel/Poppe/Mayer/Federle/Riethmüller/ Rieber 